\title{
Ceftazidime pharmacokinetics in preterm infants: Effects of renal function and gestational age
}

Objective: The objectives of this study were (1) to determine the effects of gestational age on ceftazidime pharmacokinetics in the preterm infant, (2) to relate these effects to changes in glomerular filtration rate (GFR), and (3) to establish appropriate dosage recommendations for preterm infants on day 3 of life.

Methods: Multiple-dose pharmacokinetics of ceftazidime (administered twice daily in a 25 or $50 \mathrm{mg} / \mathrm{kg}$ body weight intravenous dose) were evaluated in 136 preterm infants on day 3 of life. Blood samples were collected from an arterial catheter $0,1 / 2,1,2,4,8$, and 12 hours after the intravenous dose. An HPLC method was used to determine ceftazidime concentrations in serum. The GFR was studied simultaneously by means of the 24 -hour continuous inulin infusion technique.

Results: The total body clearance, volume of distribution, and elimination serum half-life of ceftazidime (mean \pm SD) were $55.7 \pm 34.4 \mathrm{ml} / \mathrm{hr}(37.3 \pm 11.9 \mathrm{ml} / \mathrm{hr} / \mathrm{kg}), 496 \pm 228 \mathrm{ml}(350 \pm 96 \mathrm{ml} / \mathrm{kg})$, and $6.95 \pm 2.32$ hours, respectively. The mean \pm SD peak and trough levels were $114.9 \pm 39.4$ and $33.9 \pm$ $17.8 \mathrm{mg} / \mathrm{L}$. All infants had a serum trough level above $5 \mathrm{mg} / \mathrm{L}$. Clearance and volume of distribution of ceftazidime and GFR increased significantly with increasing gestational age, whereas serum trough levels and serum half-life of ceftazidime decreased significantly with increasing gestational age. Ceftazidime clearance increased significantly with increasing GFR. Prenatal exposure to indomethacin resulted in significantly lower GFR values and ceftazidime clearances.

Conclusions: Dosage recommendations for ceftazidime administration in preterm infants during the first week of life should be based on gestational age and GFR. Additional adjustments in dosage are indicated in preterm infants who are exposed prenatally to indomethacin. (Clin Pharmacol Ther 1995;58:650-9.)

John N. van den Anker, MD, Rik C. Schoemaker, MSc, Wim C. J. Hop, MSc, Bert J. van der Heijden, MD, Allan Weber, BSc, Pieter J. J. Sauer, MD, Herman J. Neijens, MD, and Ronald de Groot, MD

Rotterdam, Leiden, and The Hague, The Netherlands

Ceftazidime, a third-generation cephalosporin, is frequently used for the treatment of bacterial infections in newborn infants. It is active against common

From the Departments of Pediatrics and Epidemiology and Biostatistics, Erasmus University and University Hospital Rotterdam/ Sophia Children's Hospital, Rotterdam; the Centre for Human Drug Research, Leiden; and the Department of Pediatrics, Juliana Children's Hospital, The Hague.

Supported by a research grant from Glaxo B. V., Zeist, The Netherlands.

Received for publication April 28, 1995; accepted July 25, 1995. Reprint requests: John N. van den Anker, MD, Sophia Children's Hospital, Dr. Molewaterplein 60, 3015 GJ Rotterdam, The Netherlands.

Copyright $(\mathcal{C} 1995$ by Mosby-Year Book, Inc.

0009-9236/95/\$5.00 + $0 \quad \mathbf{1 3 / 1 / 6 8 0 2 9}$ gram-positive neonatal pathogens such as Streptococcus agalactiae (minimal inhibitory concentration $\left[\mathrm{MIC}_{90}<0.25 \mathrm{mg} / \mathrm{L}\right.$ ) and gram-negative bacilli, including Escherichia coli $\left(\mathrm{MIC}_{90}<0.25 \mathrm{mg} / \mathrm{L}\right){ }^{1,3}$ Despite the widespread use of ceftazidime in neonatal intensive care units, the pharmacokinetics of ceftazidime in preterm infants with gestational ages of less than 30 weeks have not been studied. The pharmacokinetic parameters of ceftazidime in preterm infants with gestational ages above 30 weeks show a large variability in kinetic parameters. ${ }^{4-8}$ The currently recommended dosage for ceftazidime in preterm infants less than 4 weeks of life with a birth weight below $1200 \mathrm{gm}$ is 25 to $50 \mathrm{mg} / \mathrm{kg}$ body weight every 12 hours..$^{4-9}$ Dosage recommendations for ceftazidime are derived from 
studies that did not stratify patients according to gestational age or postnatal age. However, the glomerular filtration rate (GFR) of preterm infants increases significantly with advancing gestational age and postnatal age. ${ }^{10,11}$ This has a major effect on the pharmacokinetics of antibiotics that are eliminated mainly by glomerular filtration, as was demonstrated for amoxicillin. ${ }^{12}$ In addition, prenatal exposure to betamethasone (a drug prescribed to pregnant women with an increased risk of preterm delivery with the intention to prevent hyaline membrane disease) or indomethacin (a drug prescribed to pregnant women to inhibit preterm uterine contractions) exerts significant effects on the GFR of preterm infants in the first days of life." Ceftazidime has a low level of serum protein binding and is eliminated primarily by glomerular filtration. ${ }^{13,14}$ We therefore hypothesized that the pharmacokinetic behavior of ceftazidime in preterm infants in the first days of life would be influenced by gestational age and GFR, and this might result in higher concentrations of ceftazidime in the more preterm infants. The purpose of this study was to determine the effects of gestational age and GFR on the multiple-dose pharmacokinetics of ceftazidime in preterm infants with gestational ages between 24 and 37 weeks on day 3 of life and to establish appropriate dose and dose-interval recommendations for ceftazidime administration in preterm infants during the first week of life.

\section{METHODS}

Patients. One hundred thirty-six preterm infants with gestational ages between 24 and 37 weeks, admitted to the neonatal intensive care unit with suspected or documented septicemia, were eligible for study. The inclusion criteria were postnatal age of 3 days, stability of hemodynamic function (diuresis, $>1$ $\mathrm{ml} / \mathrm{kg}$ body weight/hr; systolic and diastolic blood pressure above the third percentile adjusted for gestational age), and normal liver function. Infants receiving nephrotoxic or inotropic drugs were excluded. All paticnts had an indwelling arterial catheter. The partial pressure of oxygen in arterial blood was kept at higher than $50 \mathrm{~mm} \mathrm{Hg}(6.66 \mathrm{kPa})$, and the oxygen saturation was kept above $92 \%$. The gestational ages of the 136 infants were estimated from the mother's menstrual history, early ultrasonography if available, and physical cxamination according to the criteria of Dubowitz et al. ${ }^{15}$ Preterm infants with gestational ages of less than 34 weeks were given ceftazidime $(25 \mathrm{mg} / \mathrm{kg}$ intravenously) every 12 hours and amoxicillin (25 $\mathrm{mg} / \mathrm{kg}$ intravenously) every 12 hours. Preterm infants with gestational ages between 34 and 37 weeks as- signed to receive therapy were given ceftazidime $(50$ $\mathrm{mg} / \mathrm{kg}$ intravenously) every 12 hours and amoxicillin (50 $\mathrm{mg} / \mathrm{kg}$ intravenously) every 12 hours. Patients with documented invasive bacterial infections received at least 10 days of intravenous therapy. Patients with sterile blood cultures and only a suspicion of infection received a total of 72 hours of therapy.

Eighty-four infants (group A) were not exposed prenatally to betamethasone or indomethacin. Twentyfive infants were exposed prenatally to indomethacin but not to betamethasone (group B). Only six infants were exposed prenatally to betamethasone but not to indomethacin (group C). Twenty-one infants were exposed prenatally to both betamethasone and indomethacin (group D). Betamethasone was administered in two intravenous doses of $12 \mathrm{mg}$ each on 2 consecutive days. This dose was repeated every week until delivery or until the thirty-second week of gestation. Indomethacin was administered in suppositories of $100 \mathrm{mg}$ each, which were given repeatedly in the presence of preterm uterine contractions.

The study protocol was approved by the Medical Ethical Committee of the University Hospital Rotterdam. Patients were enrolled only after informed consent was obtained from the parents.

Pharmacokinetic study. The multiple-dose pharmacokinetics of ceftazidime were studied on day 3 after birth. Blood samples were taken from indwelling arterial lines before administration of an intravenous bolus injection $(\mathrm{t}=0)$ and $1 / 2,1,2,4,8$, and 12 hours after administration. These sampling times were selected based on the known disposition profile for ceftazidime. Serum samples obtained after centrifugation (Merck-type Eppendorf 5414 [Eppendorf-NethelerHinz GmbH, Hamburg, Germany], $3000 \mathrm{~g}$ for 1 minute) were stored at $-70^{\circ} \mathrm{C}$.

Measurement of the GFR. The GFR was measured by the continuous inulin infusion technique on day 3 after birth. ${ }^{10,11}$ A $10 \%$ glucose-inulin solution containing $25 \mathrm{gm}$ inulin $/ \mathrm{L}$ was infused at a rate of $0.6 \mathrm{ml} / \mathrm{kg} /$ hr, beginning at time $(\mathrm{t})$ zero of the pharmacokinetic study. After 24 hours, the inulin clearance $\left(\mathrm{CL}_{\mathrm{in}}\right)$ was calculated from the infusion rate $(\mathrm{R})$, the inulin concentration in the infusate (I), and the serum inulin concentration $\left(\mathrm{P}_{\text {in }}\right)$ by the equation $\mathrm{CL}_{\text {in }}=(\mathrm{I} \times \mathrm{R}) / \mathrm{P}_{\text {in }}$. Determination of the inulin in serum was performed after acid hydrolysis in $0.3 \mathrm{mmol} / \mathrm{L}$ perchloric acid for 15 minutes at $70^{\circ} \mathrm{C}$. The fructose thus formed was measured enzymatically.

Ceftazidime assay. Analysis of serum ceftazidime concentrations was performed according to the method described by Ayrton ${ }^{16}$ with minor modifications. 
Table I. Clinical parameters of infants with or without prenatal exposure to betamethasone or indomethacin

\begin{tabular}{lccccc}
\hline & $\begin{array}{c}\text { Group } A(n=84) \\
(\text { Indo-/Beta- })\end{array}$ & $\begin{array}{c}\text { Group } B(n=25) \\
(\text { Indo }+ \text { Beta }-)\end{array}$ & $\begin{array}{c}\text { Group } C(n=6) \\
(\text { Indo-/Beta }+)\end{array}$ & $\begin{array}{c}\text { Group D }(n=21) \\
(\text { Indo }+/ \text { Beta }+)\end{array}$ & Total $(n=136)$ \\
\hline GA (wk) & $31.5 \pm 2.8^{*}$ & $28.9 \pm 2.3$ & $30.4 \pm 2.0$ & $29.2 \pm 1.3$ & $30.6 \pm 2.7$ \\
Weight (gm) & $1579 \pm 597 *$ & $1133 \pm 334$ & $1093 \pm 266$ & $1174 \pm 265$ & $1413 \pm 545$ \\
AGA (n/\%) & $72 / 86$ & $24 / 96$ & $5 / 83$ & $21 / 100$ & $122 / 90$ \\
Ventilation $(n / \%)$ & $66 / 79$ & $17 / 68$ & $3 / 50$ & $14 / 67$ & $100 / 74$ \\
RDS (n/\%) & $26 / 31$ & $5 / 20$ & $2 / 33$ & $4 / 19$ & $37 / 27$ \\
GFR (ml/min) & $0.90 \pm 0.19$ & $0.66 \pm 0.11$ & $0.93 \pm 0.16$ & $0.81 \pm 0.12$ & $0.85 \pm 0.19$ \\
\hline
\end{tabular}

Values are means $\pm \mathrm{SD}$ or numbers/percent of patients.

Indo, Indomethacin; Beta, betamethasone; -, no prenatal exposure; +, prenatal exposure; AGA, appropriate for gestational age; GA, gestational age; RDS, respiratory distress syndrome; GFR, glomerular filtration rate.

* Significantly different $(p<0.005)$ from groups B and D.

Table II. Pharmacokinetic parameters of ceftazidime on day 3 after birth in infants with or without prenatal exposure to betamethasone or indomethacin

\begin{tabular}{lccccc}
\hline & $\begin{array}{c}\text { Group A }(n=84) \\
(\text { Indo-/Beta-) }\end{array}$ & $\begin{array}{c}\text { Group B }(n=25) \\
(\text { Indo }+ \text { Beta- })\end{array}$ & $\begin{array}{c}\text { Group C }(n=6) \\
(\text { Indo-/Beta }+)\end{array}$ & $\begin{array}{c}\text { Group D }(n=21) \\
(\text { Indo }+ \text { Beta }+)\end{array}$ & Total $(n=136)$ \\
\hline $\mathrm{CL}(\mathrm{ml} / \mathrm{hr})$ & $67.9 \pm 37.6$ & $32.6 \pm 15.9^{*}$ & $37.9 \pm 13.0$ & $39.9 \pm 11.0$ & $55.7 \pm 34.4$ \\
$\mathrm{CL}(\mathrm{ml} / \mathrm{hr} / \mathrm{kg})$ & $41.0 \pm 12.2$ & $28.2 \pm 9.5 *$ & $34.5 \pm 7.2$ & $34.0 \pm 6.2$ & $37.3 \pm 11.9$ \\
$\mathrm{~V}_{\text {area }}(\mathrm{ml})$ & $560 \pm 241$ & $416 \pm 196$ & $315 \pm 54$ & $386 \pm 120$ & $496 \pm 228$ \\
$\mathrm{~V}_{\text {area }}(\mathrm{ml} / \mathrm{kg})$ & $356 \pm 94$ & $366 \pm 130$ & $294 \pm 38$ & $326 \pm 53$ & $350 \pm 96$ \\
$\mathrm{t}_{1 / 2}(\mathrm{hr})$ & $6.32 \pm 1.72$ & $9.39 \pm 3.15^{*}$ & $6.05 \pm 1.10$ & $6.83 \pm 1.57$ & $6.95 \pm 2.32$ \\
\hline
\end{tabular}

Data are mean values \pm SD.

Indo, indomethacin; Beta, betamethasone; - , no prenatal exposure; + , prenatal exposure; $C L$, Total body clearance; $V_{\text {area }}$, volume of distribution; $t 1 / 2$, elimination half-life.

*Significantly different from group A after adjustment for differences in gestational age.

HPLC-grade acetonitrile was purchased from Rathburn (Walkerburn, Scotland). The other chemicals were purchased from Aldrich-Chemie (Steinheim, Germany). All chemicals applied were of the highest grade commercially available. Chromatographic analysis was performed with a glass-prepacked $\mathrm{C}_{18}$ column $(100 \times 8 \mathrm{~mm}$, Resolve Radial Pak, Waters Chromatography, Milford, Mass.) combined with a guard column. A Waters chromatography pump (model $6000 \mathrm{~A}$, Waters Chromatography) was used to deliver the eluent: $4.8 \%(\mathrm{vol} / \mathrm{vol})$ acetonitrile and $13.5 \%$ methanol in $20 \mathrm{mmol} / \mathrm{L}$ sodium acetate buffer $(\mathrm{pH} \mathrm{3.6)}$ at a flow rate of $2 \mathrm{ml} / \mathrm{min}$. The separations were carried out at room temperature. The eluate was monitored with two Waters absorbance detectors (model 440/ wavelength $254 \mathrm{~nm}$ and model 484/wavelength 265 $\mathrm{nm}$; Waters Chromatography).

To a $50 \mu \mathrm{l}$ aliquot of the serum sample, an equal volume of $6 \%(\mathrm{vol} / \mathrm{vol})$ perchloric acid containing 50 $\mathrm{mg} / \mathrm{L}$ cephaloridine as an internal standard was added. Samples were centrifuged at $1500 \mathrm{~g}$ for 5 minutes (Eppendorf centrifuge 5412). Subsequently, $25 \mu \mathrm{l}$ was injected into the column by a Waters Intelligent Sample Processor sample injector.

A calibration curve was made by dissolving 4,12 , $25,50,100,200$, and $400 \mu \mathrm{g}$ ceftazidime per milliliter in serum. These spiked standard samples were processed according to the procedure mentioned above. A linear calibration curve was obtained over a range of 4 to $400 \mu \mathrm{g}$ ceftazidime per milliliter. Because the spiked samples of the calibration curve underwent the same processing procedure as the clinical samples, the clinical samples were converted directly from the calibration curve to actual ceftazidime concentrations per milliliter of serum. The lower limit of detection of ceftazidime in serum was $0.5 \mathrm{mg} / \mathrm{L}$. The coefficients of interassay variation at different concentrations were less than $7 \%$. The intraassay values were less than $5 \%$. Recovery of $95 \%$ of ceftazidime, which had been incubated for 24 hours at room temperature, was established.

Pharmacokinetic analysis. Pharmacokinetics were studied on the third day after birth. Kinetic data were described according to a one-compartment model. Visual inspection of individual model fits gave no indication that a model more complex than a onecompartment open model was required. Pharmacokinetic parameters were calculated with the multipledose equations described by Rowland and Tozer. ${ }^{17}$ The basic equation used was as follows:

$$
\mathrm{C}_{\mathbf{t}}=\text { Dose } / \mathrm{V}_{\text {area }} \times\left(1-\mathrm{r}^{\mathrm{N}}\right) /(1-\mathrm{r}) \times \mathrm{e}^{-\mathbf{k t}}
$$




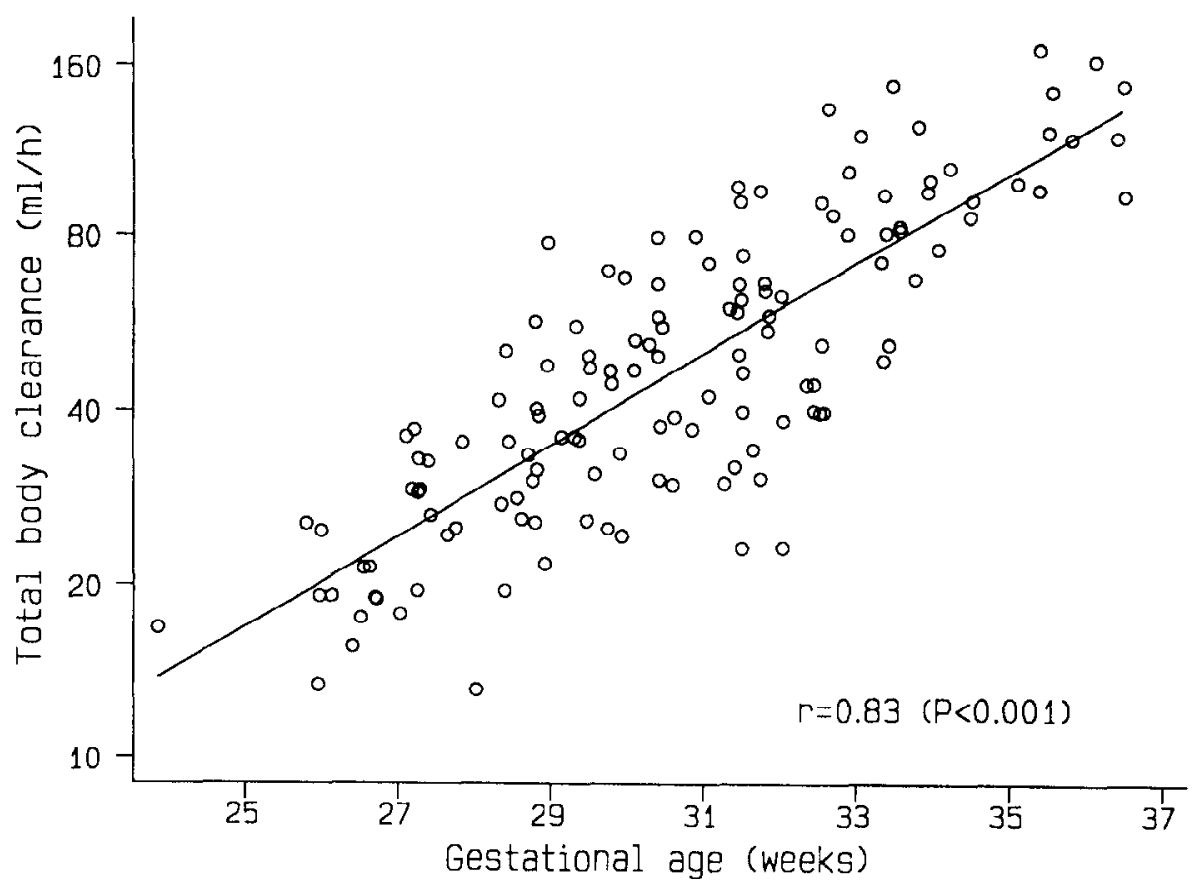

Fig. 1. Linear regression analysis of total body clearance of ceftazidime versus gestational age in 136 preterm infants on day 3 after birth. Note logarithmically transformed vertical axis.

In this equation, $C_{t}$ is the plasma concentration of ceftazidime at time $t$ after each dose, $V_{\text {area }}$ is the apparent volume of distribution, $\mathrm{N}$ is the dose number, and $\mathrm{r}=\mathrm{e}^{-\mathrm{k \tau}}$, in which $\mathrm{k}$ is the elimination rate constant and $\tau$ is the dosing interval. Because doses were given twice daily, the ceftazidime concentration-time curve was assumed attributable to the seventh dose (and the trough level at $t=0$ was assumed to be attributable to the sixth dose). 'lotal body clearance (CL) was calculated with the following equation: $C L=k$. $\mathrm{V}_{\text {area }}$. Concentration time plots showed a linear decrease over time and no indication of leveling off. Scatter was evenly distributed on log scale, indicating the need for $1 /\left(\mathrm{Ycal}^{2}\right)^{2}$ weighting. All calculations were carried out with the nonlinear regression module of SPSS/PC + V 4.0.1 (SPSS Inc., Chicago, IIl.), which uses a Levenberg-Marquardt algorithm.

To examine the different dosing strategies, based on the assumption that serum trough levels should never drop below $5 \mathrm{mg} / \mathrm{L}$, dosage recommendations for ceftazidime were calculated according to the following equation:

$$
5<\mathrm{C}_{\tau}=\frac{\mathrm{D} \cdot \mathrm{wt}}{\mathrm{V}_{\text {aiea }}} \cdot \mathrm{e}^{-\mathrm{k} \tau}
$$

In this equation $C_{\tau}$ is the serum trough concentration after the first dose, $\mathrm{D}$ the prescribed dose per kilogram body weight, wt is the weight, $\mathrm{k}$ is the elimi- nation rate constant, $\tau$ is the dosing interval, and $\mathrm{V}_{\text {area }}$ is the apparent volume of distribution of ceftazidime.

Statistical analysis. Data given are mean \pm SD unless indicated otherwise. Correlation cocfficients given are Pearson's. Comparison of groups was done with the $t$ test. Least-squares regression was used to evaluate linear relations between variables. In most of these analyses, the dependent variable had to be transformed logarithmically to obtain approximately normally distributed residuals. All $p$ values $<0.05$ (two-sided) were considered significant.

\section{RESULTS}

One hundred thirty-six neonates were enrolled in the study. Fifty-five infants (40\%) had gestational ages of less than 30 weeks. The demographic and clinical parameters of all patients are shown in Table I. The pharmacokinetic parameters of ceftazidime before and after normalization for weight and the $\mathrm{CL}_{\text {in }}$ data are indicated in Table II. The mean $\pm \mathrm{SD}$ of CL, $V_{\text {area }}$, and the elimination serum half-life $\left(\mathrm{t}_{1 / 2}\right)$ of ceftazidime were $55.7 \pm 34.4 \mathrm{ml} / \mathrm{hr}, 496 \pm 228 \mathrm{ml}$, and $6.95 \pm$ 2.32 hours, respectivcly. After correction for body weight, the mean $\pm \mathrm{SD}$ of $\mathrm{CL}$ and $\mathrm{V}_{\text {area }}$ of ceftazidime were $37.3 \pm 11.9 \mathrm{ml} / \mathrm{hr} / \mathrm{kg}$ and $350 \pm 96 \mathrm{ml} / \mathrm{kg}$, respectively. The mean \pm SD peak and trough levels were $114.9 \pm 39.4$ and $33.9 \pm 17.8 \mathrm{mg} / \mathrm{L}$, respectively. All neonates had serum trough concentrations 


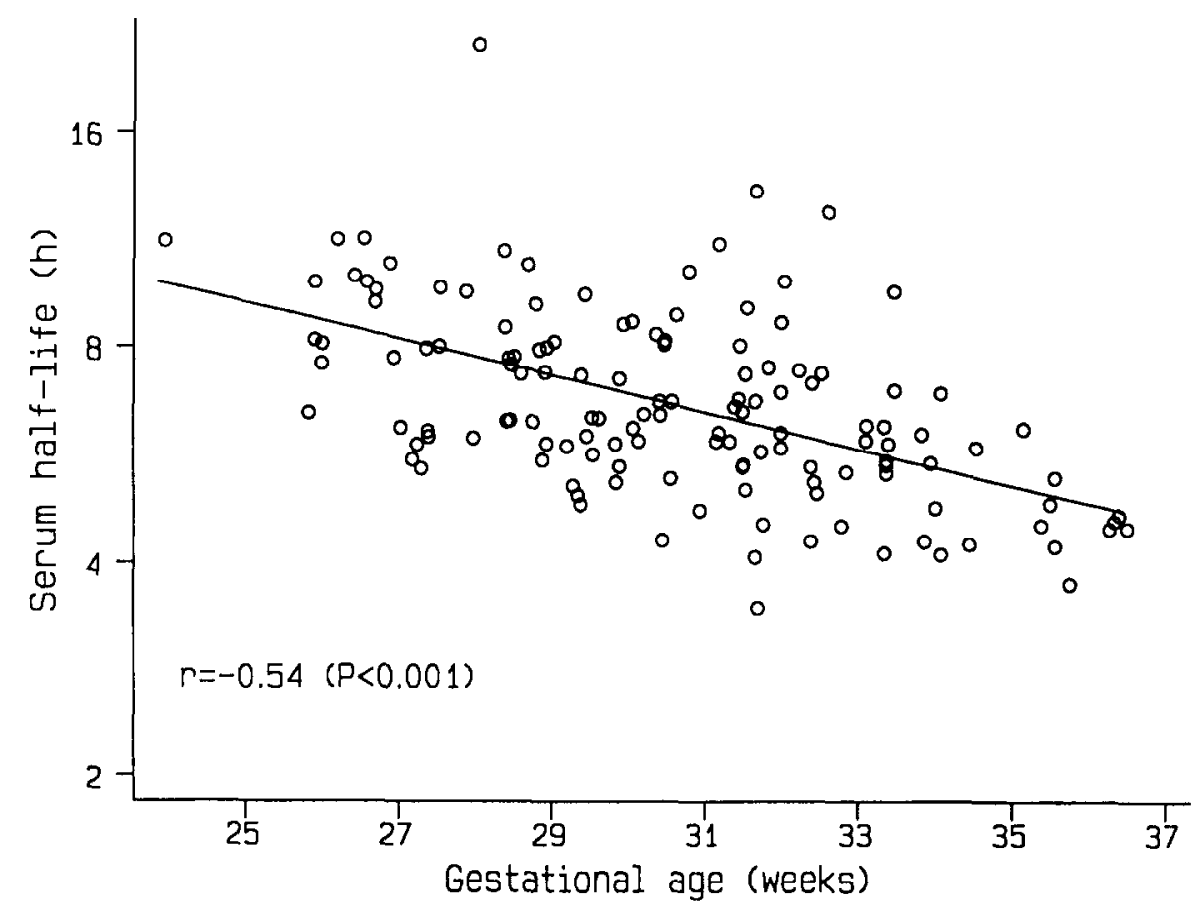

Fig. 2. Linear regression analysis of elimination serum half-life of ceftazidime versus gestational age in 136 preterm infants on day 3 after birth.

above $5 \mathrm{mg} / \mathrm{L}$. The serum trough levels of ceftazidime were high $(>40 \mathrm{mg} / \mathrm{L})$, cspecially in infants with gestational ages of less than 28 weeks.

The CL of ceftazidime $(r=0.83 ; p<0.001)$ (Fig. 1) and the $\mathrm{V}_{\text {area }}$ of ceftazidime $(r=0.74 ; p<0.001)$ increased significantly with increasing gestational age. The CL of ceftazidime $(r=0.88 ; p<0.001)$ and the $\mathrm{V}_{\text {area }}$ of ccftazidimc $(r=0.84 ; p<0.001)$ also increased significantly with weight. The correlation between gestational age and $V_{\text {area }}$ disappeared $(p=$ 0.588 ) after normalization of $\mathrm{V}_{\text {area }}$ for weight. The CL of ceftazidime per kilogram still increased significantly with gestational age $(r=0.56 ; p<0.001)$. The $\mathrm{t}_{1 / 2}$ of ccftazidime decreased significantly with gestational age ( $r=-0.54 ; p<0.001)$ (Fig. 2), as well as with weight $(r=-0.50 ; p<0.001)$.

$\mathrm{CL}_{\text {in }}$ (as a parameter of the GFR) increased significantly with increasing gestational agc $(r=0.63 ; p<$ $0.001)$. The CL of ceftazidime increased significantly with increasing $\mathrm{CL}_{\text {in }}(r=0.73 ; p<0.001)$ (Fig. 3), whereas the $t_{1 / 2}$ of ceftazidime decreased significantly with increasing $\mathrm{CL}_{\mathrm{in}}(r=-0.70 ; p<0.001)$. The reciprocal of the serum creatinine value, a useful index of glomerular filtration in clinical practice, showed a positive linear relationship with the CL of ceftazidime $(r=0.72 ; p<0.001$ ) (Fig. 4).

Assuming that serum concentrations should not be lower than $5 \mathrm{mg} / \mathrm{L}$, appropriate dosing can be achicved by administration of $10 \mathrm{mg} / \mathrm{kg}$ ccftazidime twice daily to infants with gestational ages of less than 28 wccks, $15 \mathrm{mg} / \mathrm{kg}$ twice daily to infants with gestational ages between 28 and 32 weeks, and $25 \mathrm{mg} / \mathrm{kg}$ twice daily to infants with gestational ages above 32 weeks (Fig. 5). Alternatively, appropriate dosing may also be achieved by prolonging the dosing interval to 24 hours in preterm infants with gestational ages of less than 32 weeks with $25 \mathrm{mg} / \mathrm{kg}$. These recommendations may be applied to all preterm infants in a neonatal intensive carc unit irrespective of prenatal exposure to betamethasone or indomethacin.

To study the impact of prenatal exposure to betamethasone or indomethacin on the pharmacokinetic parameters of ceftazidime, the infants were divided into four groups. Table I shows the clinical parameters of infants in these four groups. The gestational age of infants who were exposed to indomethacin prenatally with or without betamethasone (groups B and D) was significantly lower compared with the gestational age of the infants who were not exposed prenatally to betamethasone or indomethacin (group A). Table II shows the pharmacokinetic parameters of ceftazidime on day 3 after birth in infants with or without prenatal exposure to betamethasone or indomethacin. After adjustment by multiple regression for 


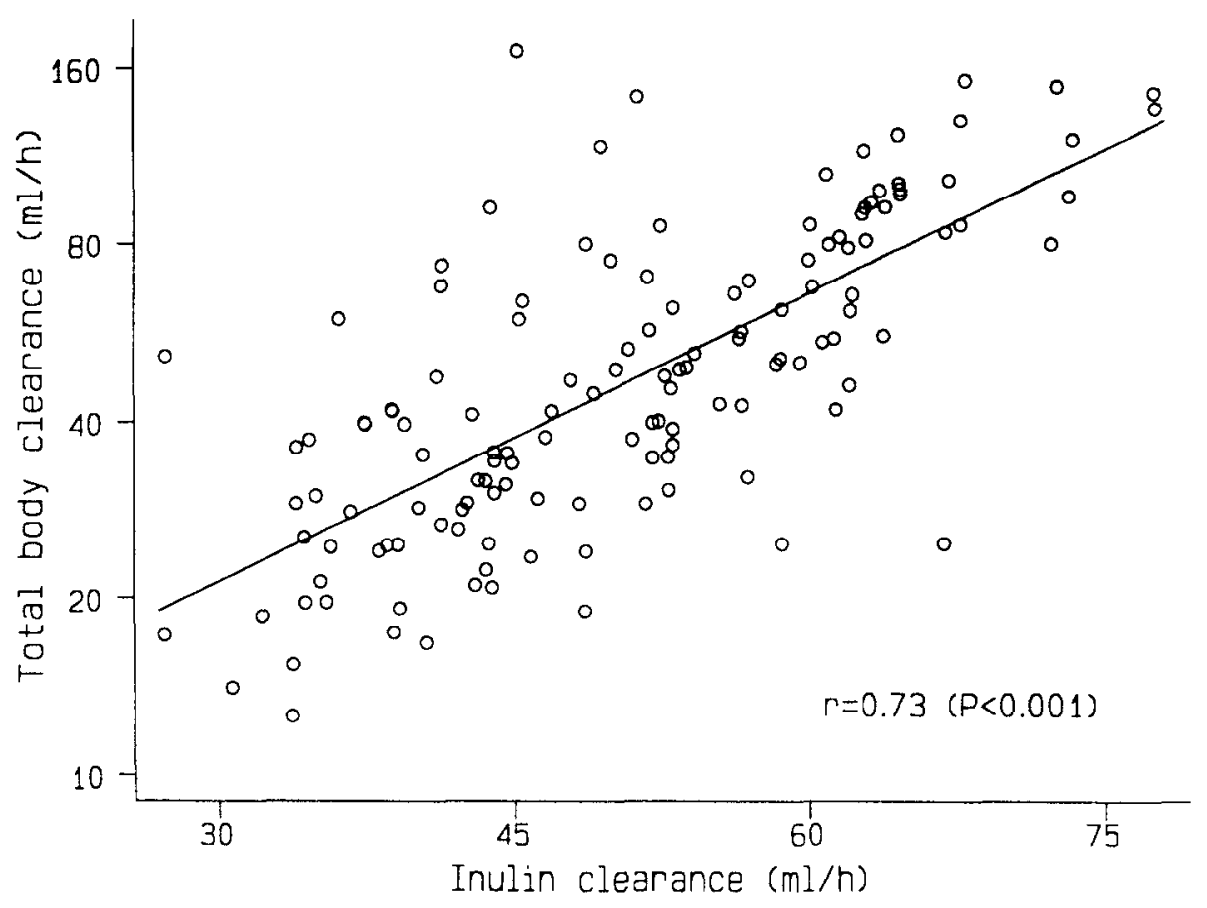

Fig. 3. Linear regression analysis of total body clearance of ceftazidime versus inulin clearance in 136 preterm infants on day 3 after birth.

the difference in gestational age between groups, the CL of ceftazidime of the patients in group B (prenatal exposure to indomethacin) was still significantly decreased and the $t_{1 / 2}$ of ceftazidime was significantly prolonged compared with the $C L$ and $t_{1 / 2}$ values of the patients in group $A$ (not exposed to indomethacin or betamethasone). The effect of prenatal exposure to indomethacin was not dependent on the gestational age or the severity of illness. No significant difference was present between the ceftazidime clearance or $t_{1 / 2}$ of the patients in group $\mathrm{D}$ (prenatal exposure to both betamethasone and indomethacin) and group A (not exposed to indomethacin or betamethasone) when adjusted for gestational age. The number of children in group $\mathrm{C}(n=6)$ was considered too small for reliable statistical analysis.

\section{DISCUSSION}

Ceftazidime is eliminated predominantly from serum by glomerular filtration. Even at relatively high concentrations, the tubular excretion of ceftazidime is negligible. ${ }^{18}$ The pharmacokinetics of ceftazidime in adults are dose independent over a dose range of 0.5 to $2.0 \mathrm{gm}$ intravenously and unaltered by repeated dosing. 14,19

The pharmacokinetic parameters of ceftazidime are different in the newborn compared with those in other pediatric age groups and adults. ${ }^{20,21}$ Furthermore, in preterm infants with gestational ages of more than 30 weeks, a large variability in these parameters has been reported. ${ }^{4,6,8,22,24}$ The major reasons for this variability are differences in gestational age and postnatal age, the route of antibiotic administration, and an insufficient number of postdose samples to calculate pharmacokinetic parameters reliably. The currently recommended dosing guidelines are based on these data. We questioned the validity of these recommendations and designed this study to establish appropriate dosage recommendations.

Our results indicate that twice-daily administration of $25 \mathrm{mg} / \mathrm{kg}$ to infants with gestational ages of less than 34 weeks and $50 \mathrm{mg} / \mathrm{kg}$ to infants with gestational ages of more than 34 weeks results in high serum levels during the entire dosing interval. The values for $t_{1 / 2}$ were increased markedly in the less mature preterm infants and showed a gestational agedependent decrease. These values were similar to those reported previously by others, ${ }^{4-6}$ whereas one study reported lower values. ${ }^{8}$ However, the latter study included only small numbers of slightly older neonates. This relationship between gestational age and $t_{1 / 2}$ was also seen for cefotaxime, but the mechanism of the decreasc of cefotaxime $t_{1 / 2}$ with increasing gestational age remained speculative. ${ }^{25}$ Gouyon et 


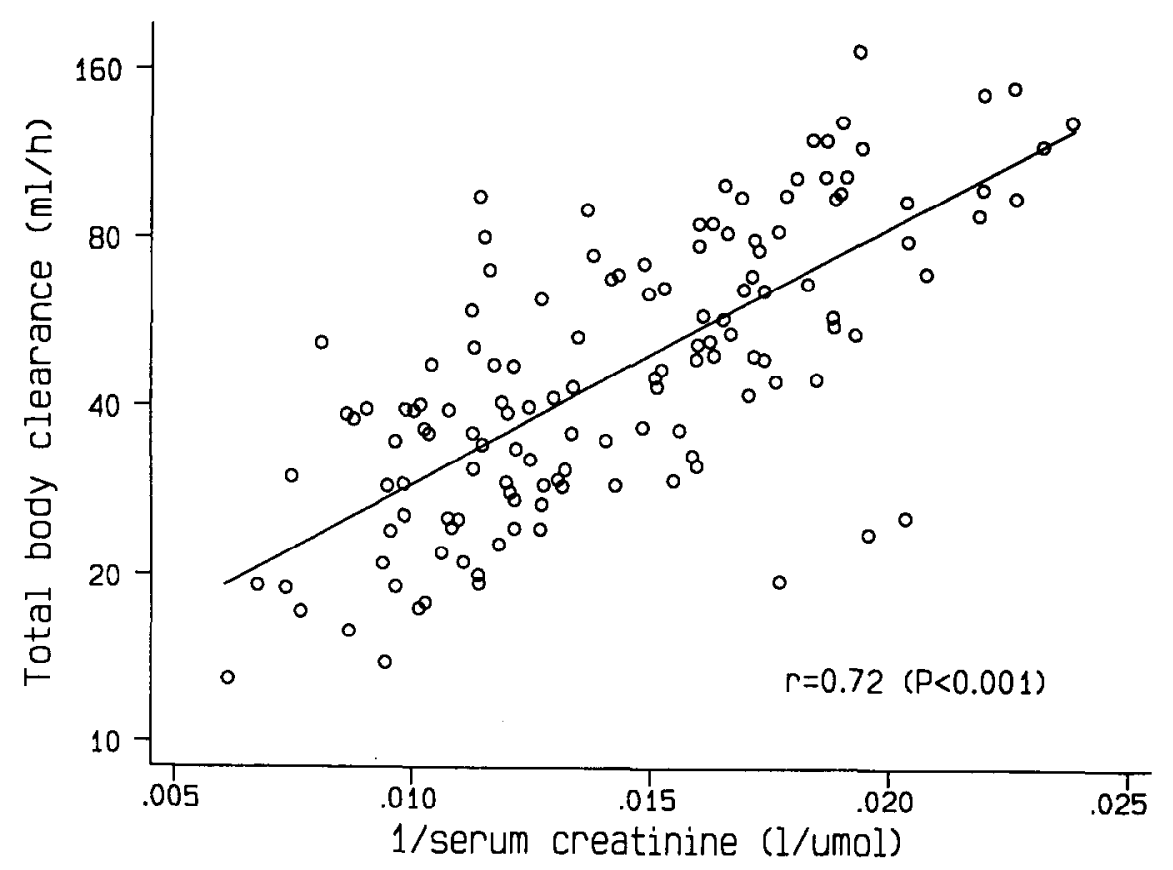

Fig. 4. Linear regression analysis of total body clearance of ceftazidime versus reciprocal of serum creatinine values in 136 preterm infants on day 3 after birth.

al. ${ }^{26}$ postulated that cefotaxime $\mathrm{CL}$ and $t_{1 / 2}$ were closely dependent on the normal maturation of renal function in newborn infants. However, they could not provide evidence for this assumption. Other studies on the disposition of cefotaxime did not provide sufficient data to document possible effects of renal development on cefotaxime pharmacokinetics. ${ }^{27-31}$

The second aim of our study was to relate the effects of gestational age on the pharmacokinetics of ceftazidime to changes in GFR. Our results demonstrate the presence of a gestational age-dependent increase of the GFR in these preterm infants. These data are in agreement with those from other studies in which a positive linear relationship between the gestational age and the GFR was demonstrated. ${ }^{11,32.33}$ The positive relationship ( $r=0.73 ; p<0.001)$ between the GFR and the CL of ceftazidime indicates that glomerular filtration has an important effect on the CL of ceftazidime. However, the variability in the CL of ceftazidime exceeds that of the $\mathrm{CL}_{\mathrm{in}}$ (Fig. 3). This indicates that ceftazidime is not eliminated by glomerular filtration alone. We propose that tubular reabsorption or tubular secretion is involved in the renal handling of ceftazidime in preterm infants.

The third aim of this study was to calculate dose recommendations for ceftazidime that may be used during the first week of life. An optimal dose regimen should result in a high clinical efficacy and a minimal chance of toxicity. To ensure clinical efficacy, serum concentrations of ceftazidime should be above the MIC of ceftazidime for major neonatal pathogens such as $S$. agalactiae $\left(\mathrm{MIC}_{90}<0.25 \mathrm{mg} / \mathrm{L}\right)$ and $E$. coli $\left(\mathrm{MIC}_{90}<0.25 \mathrm{mg} / \mathrm{L}\right)^{2,3}$ In our preterm infants, serum concentrations of ceftazidime were sufficiently high to obtain maximal clinical efficacy. However, all betalactam antibiotics are neurotoxic to some extent. ${ }^{34,35}$ In adults ceftazidime has been reported to cause encephalopathy, hallucinations, confusion, and neuromuscular excitability. ${ }^{36-40}$ In the rat model a dosedependent suppressive effect of $\beta$-lactam antibiotics has been demonstrated on the differentiation and proliferation of oligodendroglia. ${ }^{41}$ In addition to this potential neurotoxic side effect, high concentrations of ceftazidime may also result in inhibition of cell proliferation in cultured human myeloid precursor and lymphoid cells. ${ }^{42}$ This may lead to neutropenia and impairment of cellular and humoral immune responses. The above-described toxicity profile indicates that modification of the dose of ceftazidime in the preterm infant should be considered to prevent potential druginduced toxicity. However, ceftazidime-related side effects or differences in efficacy could not be demonstrated despite the large variability in levels of ceftazidime.

The presence of high serum trough concentrations and a prolonged $t_{1 / 2}$ suggests that dosage adjustments 


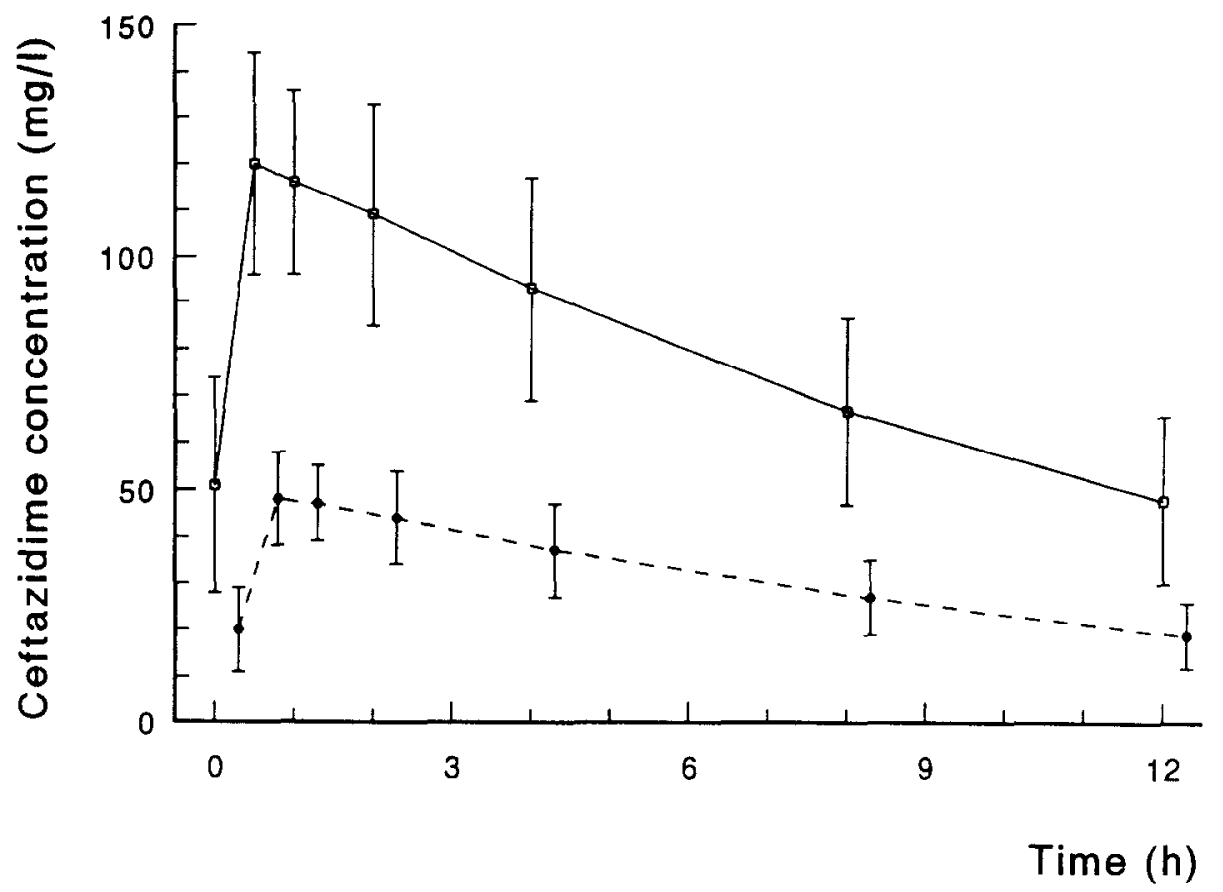

Fig. 5. Serum drug concentration-time profiles of ceftazidime $(25 \mathrm{mg} / \mathrm{kg}$ body weight) in 27 preterm infants with gestational ages of less than 28 weeks on day 3 after birth (solid line) versus predicted serum drug concentration-time profiles of ceftazidime $(10 \mathrm{mg} / \mathrm{kg}$ body weight) in same infants (broken line).

are needed in this patient population. Our data indicate that the low GFR is responsible primarily for the decreased ceftazidime CL. However, ceftazidime CL is also dependent on gestational age. Because the determination of gestational age is much easier than the measurement of the GFR, we suggest that dose recommendations of ceftazidime in the preterm infant should be based primarily on gestational age. This approach is supported by the stronger correlation between ceftazidime $\mathrm{CL}$ and gestational age $(r=0.83)$ compared with the correlation between ceftazidime $\mathrm{CL}$ and $\mathrm{Cl}_{\mathrm{in}}$ $(r-0.73)$.

To calculate dosage recommendations, infants were stratified into three groups: gestational age less than 28 weeks, 28 to 32 weeks, and 32 to 37 weeks. We used a model in which a trough level of $5 \mathrm{mg} / \mathrm{L}$ was chosen as the minimum level desired for appropriate bacterial killing of the major neonatal microorganisms. Two different strategies were used for the calculations. First, dosage recommendations were calculated according to a fixed dosing interval of 12 hours. Alternatively, appropriate dosing may also be achieved by prolonging the dosing interval to 24 hours in infants with gestational ages of less than 32 weeks. These recommendations may be applied to a broad population of preterm infants because they are derived from results obtained from all preterm infants in a neonatal intensive care unit irrespective of prenatal exposure to betamethasone or indomethacin. Further studies will be necessary to determine whether invasive bacterial infections have a significant effect on the pharmacokinetics of ceftazidime in the first 2 weeks of life.

We recently reported that prenatal exposure to betamethasone or indomethacin exerted significant effects on the GFR of preterm infants in the first days of life. ${ }^{11}$ We therefore studied the effects of prenatal exposure to betamethasone and indomethacin on the pharmacokinetics of ceftazidime. Most pregnant women who were treated with betamethasone were also treated with indomethacin to inhibit preterm uterine contractions. The number of patients exposed to betamethasone alone was therefore too small to perform a separate analysis. Our analysis indicates that the gestational age-adjusted ceftazidime CL of the infants who were exposed prenatally to both betamethasone and indomethacin was significantly higher compared with the $\mathrm{CL}$ of ceftazidime of the infants who were exposed prenatally to indomethacin alone. In addition, the gestational age-adjusted CL of ceftazidime of the infants who were exposed prenatally to both 
drugs was not different from the CL of ceftazidime of the infants who were not exposed at all (group A). The gestational age-adjusted $V_{\text {area }}$ of ceftazidime did not show any significant differences between groups A, B, and D. Consequently, the gestational age-adjusted $t_{1 / 2}$ of ceftazidime of the infants who were exposed prenatally to both betamethasone and indomethacin was significantly shortened compared with the $t_{1 / 2}$ of ceftazidime of the infants who were exposed prenatally to indomethacin alone. In addition, the gestational ageadjusted $t_{1 / 2}$ of the infants who were exposed prenatally to both drugs was not different from the $t_{1 / 2}$ of the infants who were not exposed at all (group A).

These results clearly indicate that prenatal exposure to indomethacin alone significantly decreases ceftazidime CL and increases the $t_{1 / 2}$ of ceftazidime. The coadministration of betamethasone prevents these changes. We therefore advocate that additional dosage adjustments in the first week of life are needed after prenatal exposure to indomethacin, when this is not combined with the use of betamethasone. The recommended dosage for infants with gestational ages of less than 28 weeks should be adjusted to $7.5 \mathrm{mg} / \mathrm{kg}$ body weight every 12 hours, and for infants with gestational ages between 28 and 32 weeks this should be adjusted to $10 \mathrm{mg} / \mathrm{kg}$ body weight every 12 hours.

Prescription of indomethacin as a tocolytic agent is much more restricted in the United States than in The Netherlands. This has been caused by reports about negative effects on fetal and neonatal renal and cardiovascular function. ${ }^{43-45}$ Our data demonstrate that there is an effect of maternally administered indomethacin on renal function in the newborn during the first 3 days of life. On day 10 after birth, this effect could no longer be detected. Although renal toxicity was reversible, it may result in metabolic and volume derangements in addition to potential drug overdosing. These data are in agreement with the lower urine output and higher serum creatinine concentrations that were seen during the first 3 days of life in preterm infants delivered at or before 30 weeks' gestation whose mothers had been treated with indomethacin. ${ }^{46}$ Other complications seen after prenatal exposure to indomethacin are necrotizing enterocolitis, intracranial hemorrhage, and a patent ductus arteriosus. ${ }^{46}$ Indomethacin is an effective tocolytic drug that unfortunately also increases the risk of complications associated with preterm birth. Prospective studies are needed to investigate whether the efficacy of indomethacin as a tocolytic agent outweighs the risk of these complications.

In summary, dosage recommendations for ceftazi- dime in preterm infants for the first week of life should be based on gestational age and GFR, and in preterm infants who are prenatally exposed to indomethacin, additional dosage adjustments are indicated.

\section{References}

1. De Louvois J, Dagan R, Tessin I. A comparison of ceftazidime and aminoglycoside based regimens as empirical treatment in 1316 cases of suspected sepsis in the newborn. Eur J Pediatr 1992;151:876-84.

2. Gentry LO. Antimicrobial activity, pharmacokinetics, therapeutic indications and adverse reactions of ceftazidime. Pharmacotherapy 1985;5:254-67.

3. Neu HC. In vitro activity of ceftazidime, a beta-lactamase stable cephalosporin. J Antimicrob Chemother 1981;8:131-4.

4. McCracken GH, Threlkeld N, Thomas ML. Pharmacokinetics of ceftazidime in newborn infants. Antimicrob Agents Chemother 1984;26:583-4.

5. Low DC, Bissenden JG, Wise R. Ceftazidime in neonatal infections. Arch Dis Child 1985;60:360-4.

6. Mulhall A, De Louvois J. The pharmacokinetics and safety of ceftazidime in the neonate. J Antimicrob Chemother 1985; 15:97-103.

7. Boccazzi A, Rizzo M, Caccamo ML, Assael BM. Comparison of the concentrations of ceftazidime in the serum of newborn infants after intravenous and intramuscular administration. Antimicrob Agents Chemother 1983;24:955-6.

8. Prinsloo JG, Delport SD, Moncrieff J, Paton AM. A preliminary pharmacokinetic study of ceftazidime in premature, newborn and small infants. J Antimicrob Chemother 1983;12:361-4.

9. Prober CG, Stevenson DK, Benitz WE. The use of antibiotics in neonates weighing less than 1200 grams. Pediatr Infect Dis J 1990;9:111-21.

10. Van der Heijden AJ, Grose WFA, Ambagtsheer JJ, Provoost AP, Wolff ED, Sauer PJJ. Glomerular filtration rate in the preterm infant: the relation to gestational and postnatal age. Eur J Pediatr 1988;148:24-8.

11. Van den Anker JN, Hop WCJ, De Groot R, et al. Effects of prenatal exposure to betamethasone and indomethacin on the glomerular filtration rate in the preterm infant. Pediatr Res 1994;36:578-81.

12. Huisman-de Boer JJ, Van den Anker JN, Vogel M, Goessens WHF, Schoemaker RC, De Groot R. Amoxicillin pharmacokinetics in preterm infants with gestational ages of less than 32 weeks. Antimicrob Agents Chemother 1995;39:431-4.

13. Balant L, Dayer P, Auckenthaler R. Clinical pharmacokinetics of the third generation cephalosporins. Clin Pharmacokinet 1985;10:101-43.

14. Harding SM, Monro AJ, Thronton JE, Ayrton J, Hogg MIJ. The comparative pharmacokinetics of ceftazidime and cefotaxime in healthy volunteers. J Antimicrob Chemother 1981;8:263-72. 
15. Dubowitz LMS, Dubowitz V, Goldberg C. Clinical assessment of gestational age in the newborn infant. J Pediatr 1970;77:1-10.

16. Ayrton J. Assay of ceftazidime in biological fluids using high-pressure liquid chromatography. J Antimicrob Chemother 1981;8:227-31.

17. Rowland M, Tozer TN. Amount of drug in the body on accumulation. In: Rowland M, Tozer TN, eds. Clinical pharmacokinetics: concepts and application. 2nd ed. Philadelphia: Lea \& Febiger, 1989:473-5.

18. Verhagen CA, Mattie H, Van Strijen E. The renal clearance of cefuroxime and ceftazidime and the effect of probenecid on their tubular excretion. Br J Clin Pharmacol 1994;37:193-7.

19. Harding SM, Harper PB. The pharmacokinetic behaviour of ceftazidime in man and the relationship between serum levels and the in vitro susceptibility of clinical isolates. Infection 1983;11:S49-53.

20. Luthy R, Blaser J, Bonetti A, Simmen H, Wise R, Siegenthaler W. Comparative multiple-dose pharmacokinetics of cefotaxime, moxalactam, and ceftazidime. Antimicrob Agents Chemother 1981;20:567-75.

21. Yuk-Choi JH, Nightingale $\mathrm{CH}$, Williams TW. Considerations in dosage selection for third generation cephalosporins. Clin Pharmacokinet 1992;22:132-43.

22. Amato M, Schaad UB. Preliminary experience with ceftazidime monotherapy in perinatal infection. Helv Paediatr Acta 1987;42:297-303.

23. Begue P. Safran C, Quiniou F, Lasfargues G, Quinet B. Comparative pharmacokinetics of four new cephalosporins: moxalactam, cefotaxime, cefoperazone and ceftazidime in neonates. Dev Pharmacol Ther 1984;7:105-8.

24. Tessin I, Thiringer K, Trollfors B, Brorson JE. Comparison of serum concentrations of ceftazidime and tobramycin in newborn infants. Eur J Pediatr 1988;147: 405-7.

25. Kearns GL, Jacobs RF, Thomas BR, Darville TL, Trang JM. Ccfotaxime and desacetyl-cefotaxime pharmacoki netics in very low birth weight neonates. J Pediatr 1989;114:461-7.

26. Gouyon JB, Pechinot A, Safran C, Chretien P, Sandre D, Kazmierczak A. Pharmacokinetics of cefotaxime in preterm infants. Dev Pharmacol Ther 1990;14:29-34.

27. De Louvois J, Mulhall A, Hurley R. The safety and pharmacokinetics of cefotaxime in the treatment of neonates. Pediatr Pharmacol 1982;2:275-84.

28. McCracken GH, Threlkeld NE, Thomas ML. Pharmacokinetics of cefotaxime in newborn infants. Antimicrob Agents Chemother 1982;21:683-4.

29. Kafetzis DA, Brater DC, Kapiki AN, Papas CV, Dellagrammaticas H, Papadotos CJ. Treatment of severe neonatal infections with cefotaxime: efficacy and pharmacokinetics. J Pediatr 1982;100:483-9.

30. Baird-Lambert J, Doyle PE, Thomas D, Cvejic M,
Buchanan N. Pharmacokinetics of cefotaxime in neonates. J Antimicrob Chemother 1984;13:471-7.

31. Crooks J, White LO, Burville LJ, Speidel BD, Reeves DS. Pharmacokinetics of cefotaxime and desacetyl-cefotaxime in neonates. J Antimicrob Chemother 1984; 14(suppl):97-101.

32. Fawer CL, Torrado A, Guignard JP. Maturation of renal function in full-term and premature neonates. Helv Paediatr Acta 1979;34:11-21.

33. Van der Heijden AJ, Grose WFA, Ambagtsheer JJ, Provoost AP, Wolff ED, Sauer PJJ. Glomerular filtration rate in the preterm infant: the relation to gestational and postnatal age. Eur J Pediatr 1988;148:24-8.

34. Snavely SR, Hodges GR. The neurotoxicity of antibacterial agents. Ann Intern Med 1984;101:92-104.

35. Schliamser SE, Cars O, Norrby SR. Neurotoxicity of beta-lactam antibiotics: predisposing factors and pathogenesis. J Antimicrob Chemother 1991;27:405-25.

36. Douglas MA, Quandt CM, Stanley DA. Ceftazidimeinduced encephalopathy in a patient with renal impairment. Arch Neurol 1988;45:936-7.

37. Al-Zahawi MF, Sprott MS, Hendrick DJ. Hallucinations in association with ceftazidime [Letter]. $\mathrm{Br}$ Med J 1988;297:858.

38. Geycr J, Hoffler D, Demers HG, Nicmeyer R. Cephalosporin-induced encephalopathy in uremic patients [Letter]. Nephron 1988;48:237.

39. Slaker RA, Danielson B. Neurotoxicity associated with ceftazidime therapy in geriatric patients with renal dysfunction. Pharmacotherapy 1991;11:351-2.

40. Jackson GD, Berkovic SF. Ceftazidime encephalopathy: absence status and toxic hallucinations. J Neurol Neurosurg Psychiatry 1992;55:333-4.

41. Schaad UB, Guenin K, Steffen C', Herschkowitz N. Effects of antimicrobial agents used for therapy of CNS infections on dissociated brain cell cultures. Pedialr Res 1988;24:367-72.

42. Neftel $K \Lambda$, Hauser SP, Muller MR. Inhibition of granulopoiesis in vivo and in vitro by beta-lactam antibiotics. I Infect Dis 1985;152:90-8.

43. Goldenberg RL, Davis RO, Baker RC. Indomethacininduced oligohydramnios. Am J Obstet Gynecol 1989; 160:1196-7.

44. Moise KJ Jr, Huhta JC, Sharif DS, et al. Indomethacin in the treatment of premature labor: effects on the fetal ductus arteriosus. N Engl J Med 1988;319:327-31.

45. Vanhaesebrouck $P$, Thiery $M$, Leroy JG, et al. Oligohydramnios, renal insufficiency, and ileal perforation in preterm infants after intrauterine exposure to indomethacin. J Pediatr 1988;113:738-43.

46. Norton ME, Merrill J, Cooper BAB, Kuller JA, Clyman RI. Neonatal complications after the administration of indomethacin for preterm labor. N Engl J Med 1993; 329:1602-7. 